\title{
Delorme's Procedure for Complete Rectal Prolapse: Does It Still Have It's Own Role?
}

\author{
Sooho Lee, Bong-Hyeon Kye, Hyung-Jin Kim, Hyeon-Min Cho, Jun-Gi Kim ${ }^{1}$ \\ Department of Surgery, St. Vincent's Hospital, The Catholic University of Korea, Suwon; ${ }^{1}$ Department of Surgery, Seoul St. Mary's Hospital, \\ The Catholic University of Korea, Seoul, Korea
}

Purpose: Although there are more than a hundred techniques, including the transabdominal and the perineal approaches, for the repair of the rectal prolapsed, none of them is perfect. The best repair should be chosen not only to correct the prolapse but also to restore defecatory function and to improve fecal incontinence throughout the patient's lifetime. The aim of this retrospective review is to evaluate clinical outcomes of the Delorme's procedure for the management of the complete rectal prolapse.

Methods: A total of 19 patients (13 females and 6 males) with complete rectal prolapses were treated by using the Delorme's procedure in St. Vincent's Hospital, The Catholic University of Korea, from February 1997 to February 2007. Postoperative anal incontinence was evaluated using the Cleveland Clinic Incontinence Score.

Results: All 19 patients had incontinence to liquid stool, solid stool, and/or flatus preoperatively. Three (15.8\%) patients reported recurrence of the rectal prolapse (at 6, 18, 29 months, respectively, after the operation). Information on postoperative incontinence was available for 16 of the 19 patients. Twelve of the 16 patients (75\%) reported improved continence (5 [31.3\%] were improved and 7 [43.7\%] completely recovered from incontinence) while 4 patients had unchanged incontinence symptoms. One (6.3\%) patient who did not have constipation preoperatively developed constipation after the operation.

Conclusion: The Delorme's procedure is associated with a marked improvement in anal continence, relatively low recurrence rates, and low incidence of postoperative constipation. This allows us to conclude that this procedure still has its own role in selected patients.

Keywords: Incontinence; Delorme’s procedure; Rectal prolapse

\section{INTRODUCTION}

The rectal prolapse can affect patients at any age. However, the peak age of incidence is the seventh decade in women whereas the relatively few men who are afflicted with the syndrome may develop the prolapse at the age of 40 years. Almost $90 \%$ of adult

Received: May 11, 2011 Revised: October 18, 2011

Accepted: December 20, 2011

Correspondence to: Hyeon-Min Cho, M.D.

Department of Surgery, St. Vincent's Hospital, The Catholic University of

Korea, 93 Jungbu-daero, Paldal-gu, Suwon 442-723, Korea

Tel: +82-31-249-7084, Fax: +82-31-247-5347

E-mail: hmcho@catholic.ac.kr

(C) 2012 The Korean Society of Coloproctology

This is an open-access article distributed under the terms of the Creative Commons Attribution NonCommercial License (http://creativecommons.org/licenses/by-nc/3.0) which permits unrestricted non-

commercial use, distribution, and reproduction in any medium, provided the original work is properly cited. patients are females in the postmenopausal period and often with a multiparous history. Also, histories of constipation and previous pelvic surgery are associated with this disease.

The best repair should be chosen not only to correct the prolapse but also to restore defecatory function and to improve fecal incontinence throughout the patient's lifetime. Although there are more than a hundred techniques, including the transabdominal and the perineal approaches, for the repair of the rectal prolapsed, none of them is perfect. According to the literature, the procedure most commonly performed in the management of the rectal prolapse is the abdominal rectopexy [1].

The Delorme's procedure for the complete rectal prolapse was first described by the French military surgeon Edmond Delorme in 1900 [2]. Perineal approaches to rectal prolapse are safe and have some advantages compared with transabdominal approaches. The Delorme's procedure can be performed under local and/or 
regional anesthesia, making it ideal for patients with significant comorbidities [2-4]. In addition, a laparotomy can be avoided in patients who had undergone previous laparotomies, and some risks of acute small bowel injury and future small bowel obstruction can be avoided. Postoperative hospital stay and convalescence are generally shorter with perineal approaches, but some reports of high recurrence rates (5 to $22 \%$ ), high complication rates, poor anatomic and functional outcomes, and lack of sufficient data regarding the durability of the Delorme repair have kept it from being universally accepted as the initial treatment for the rectal prolapse $[3,5]$. However, in spite of the above-mentioned facts, the Delorme's technique has been recently revitalized. The aim of the present study is to evaluate the clinical and the functional outcomes of the Delorme's procedure for the management of the complete rectal prolapse.

\section{METHODS}

A total of 19 patients (13 females and 6 males) with complete rectal prolapses were treated by using the Delorme's technique at St. Vincent's Hospital, The Catholic University of Korea from February 1997 to February 2007. Two patients underwent surgery for a recurrent rectal prolapse that developed after a stapled transanal rectal resection, while 17 underwent their first rectal prolapse repair. After institutional review board approval had been obtained (Subject No: VS10RISI0127), we retrospectively investigated the clinical and the functional outcomes in these patients by using chart reviews and phone calls.

Preoperative diagnostic tests included physical examination, and colonoscopy or barium enema was performed in all patients. The bowel was cleaned using a balanced polyethyleneglycol solution, and an antimicrobial prophylaxis was applied. The Delorme's procedure was performed by two colorectal surgeons in all patients. The mean follow-up period was 54 months (range, 17 to

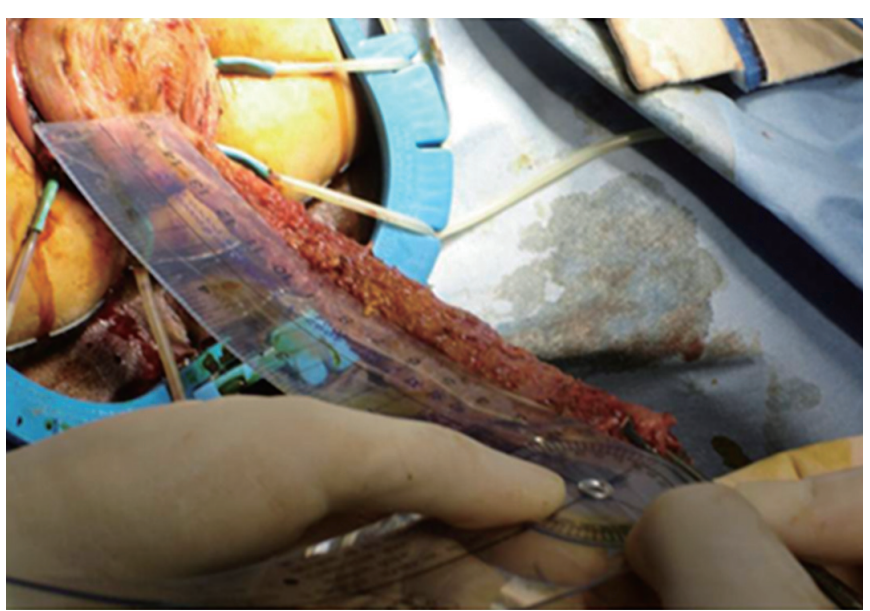

Fig. 1. Mucosal and submucosal sleeve was dissected to the prolapse's vertex.
137 months). Enrolled patients visited at one week after discharge, and we had regular follow-ups at postoperative 1 month, 3 months, and 6 months, and then annually. Postoperative anal incontinence was evaluated at every hospital visit by using the Cleveland Clinic Incontinence Score (CCIS) [6].

\section{Surgical technique}

Under general endotracheal anesthesia, the lithotomy position was used for all patients. With a completely prolapsed rectum, 1:200,000 epinephrine was injected into the submucosal plane above the dentate line. A circular incision was made, using an electric scalpel, through the mucosal and the submucosal layers $1 \mathrm{~cm}$ above the dentate line, and a sleeve was dissected, which revealed the rectal circular muscular layer, to the prolapse's vertex (Fig. 1). Twelve absorbable stitches with longitudinal sutures were applied to plicate the rectal musculature in order to reduce and invaginate it. After the dissected mucosa had been excised, the procedure was ended by using the previous stitches from the proximal to the distal mucosa just above the dentate line. After surgery, oral intake was restricted during the first three postoperative days.

\section{RESULTS}

The mean age was $67.2 \pm 16.6$ years (range, 43 to 89 years). One patient underwent concomitant uterine prolapse repair (Table 1). Table 2 shows the underlying diseases in the patients with American Society of Anesthesiologists (ASA) II and III who underwent

Table 1. Characteristics of patients undergoing the Delorme's procedure $(\mathrm{n}=19)$

\begin{tabular}{lc}
\hline Characteristic & No. of patients (\%) \\
\hline Sex & $6(32)$ \\
Male & $13(68)$ \\
Female & \\
ASA & $12(63)$ \\
I & $4(21)$ \\
॥ & $3(16)$ \\
III & \\
Previous operative history for the rectal prolapse & $2(11)$ \\
Yes & $17(89)$ \\
No & \\
Concomitant pelvic floor disease & $1(5)^{\mathrm{a}}$ \\
Yes & $18(95)$ \\
No & \\
Preoperative incontinence & $19(100)$ \\
Yes & $0(0)$ \\
No &
\end{tabular}

ASA, American Society of Anesthesiologists.

aShe had a rectal prolapse and a uterine prolapse concomitantly. 
Volume 28, Number 1, 2012

the Delorme's procedure. At surgery, the mean symptom duration was 95 months (range, 1 to 240 months). The mean operation time was 186 minutes (range, 120 to 240 minutes). No patient needed blood transfusion, and no intraoperative complications were noted. The mean postoperative hospital stay was 12 days (range, 7 to 26 days). One patient (5\%) 84 years old, died of sepsis due to preexistent pneumonia on the 26th day after the procedure. No other mortality related to the operation was recorded. Also, no major morbidities, such as anastomosis stricture, bleeding, or disruption of the anastomosis, were noted.

At follow-up, three patients (16\%) had died of causes not related to the rectal prolapse or the surgery. Three patients (15.8\%) reported

Table 2. Underlying diseases in patients with ASA II and III undergoing the Delorme's procedure

\begin{tabular}{lc}
\hline Comorbid disease & No. of patients \\
\hline Hypertention & 5 \\
Bronchial asthma & 3 \\
COPD & 1 \\
Pneumonia & 1 \\
MR & 1 \\
CRF & 1 \\
Spinal stenosis & 1 \\
\hline
\end{tabular}

Four patients had more than two underlying diseases.

ASA, American Society of Anesthesiologists; COPD, chronic obstructive pulmonary disease; MR, mitral valve regurgitation; CRF, chronic renal failure. recurrence of the rectal prolapsed (at 6, 18, and 29 months, respectively, after the operation). All 19 patients had incontinence to liquid stool, solid stool, and/or flatus preoperatively. Functional outcome could be evaluated in 16 of 19 patients. Twelve (75\%) of those 16 patients reported improved continence (5 [31.3\%] were improved and 7 [43.7\%] were completely recovered from incontinence) while 4 patients had unchanged incontinence (Fig. 2). The CCISs at the end of follow-up were as follows: 7 patients had 0,3 had 4, 3 had 6, 1 had 8, and 2 had 9 (Table 3). One patient (9\%) without constipation preoperatively developed constipation after the operation.

\section{DISCUSSION}

Many procedures through the abdominal and the perineal routes have been described for the treatment of the complete rectal prolapse. The advantages of the Delorme's procedure versus abdominal techniques for the management of the rectal prolapse include 1) low morbidity and mortality $[1,7,8], 2)$ no risk of impotence, which is in contrast with the abdominal rectopexy where pelvic nerves (erection problems) or hypogastric nerves (ejaculation problems) may be damaged $[1,2], 3)$ the feasibility of using spinal anesthesia, 4) short hospital stay, 5) early oral feeding (depending on the patients' associated conditions), and 6) patient comfort, with little or no postoperative pain. Thus, the Delorme's procedure may be recommended both for young and adult males to prevent potential impotence and for weakened or elderly patients [2]. The literature also indicates that the Delorme's procedure may be indi-

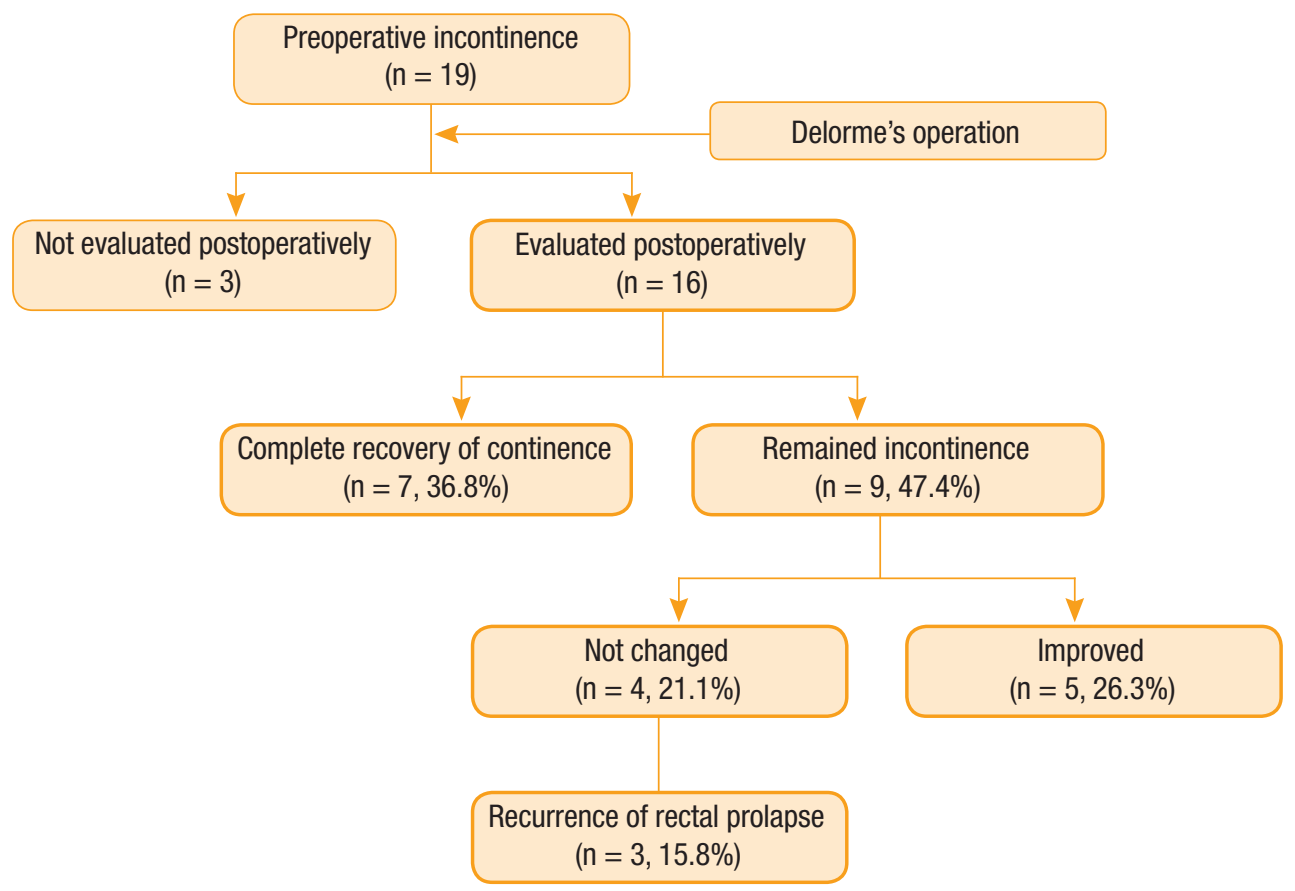

Fig. 2. Status of continence in 19 patients undergoing the Delorme's procedure. 
Table 3. Postoperative outcomes of all 19 patients undergoing the Delorme's procedure

\begin{tabular}{|c|c|c|c|c|}
\hline Age/Sex & Continence & CCIS & Constipation & Recurrence \\
\hline $83 / F$ & Improved & 4 & No & No \\
\hline $86 / F$ & Improved & 6 & No & No \\
\hline $81 / F$ & Improved & 4 & No & No \\
\hline $60 / F$ & Not changed & 9 & No & yes (29 mo later) \\
\hline $75 / F$ & $\mathrm{CR}$ & 0 & No & No \\
\hline $44 / \mathrm{M}$ & Not changed & 6 & No & No \\
\hline 45/M & $\mathrm{CR}$ & 0 & No & No \\
\hline 43/M & Not changed & 9 & No & yes (6 mo later) \\
\hline $66 / F$ & Improved & 4 & No & No \\
\hline $86 / F$ & NA & NA & NA & NA \\
\hline $84 / F$ & NA & NA & NA & No \\
\hline $89 / F$ & Not changed & 8 & No & yes (18 mo later) \\
\hline $47 / F$ & $\mathrm{CR}$ & 0 & No & No \\
\hline $57 / F$ & Improved & 6 & No & No \\
\hline 78/M & $\mathrm{CR}$ & 0 & Yes & No \\
\hline $83 / F$ & NA & NA & NA & NA \\
\hline $55 / \mathrm{M}$ & $\mathrm{CR}$ & 0 & No & No \\
\hline $63 / F$ & CR & 0 & No & No \\
\hline $51 / \mathrm{M}$ & $\mathrm{CR}$ & 0 & No & No \\
\hline
\end{tabular}

CCIS, Cleveland Clinic Incontinence Score;CR, complete recovery of continence; NA, not available.

Table 4. Clinical results of the Delorme's operation for complete rectal prolapse in the published literature

\begin{tabular}{|c|c|c|c|c|c|c|c|}
\hline Author & Year & $\begin{array}{c}\text { No. of } \\
\text { patients }\end{array}$ & $\begin{array}{l}\text { Recurrence } \\
\text { (\%) }\end{array}$ & $\begin{array}{c}\text { Postoperative } \\
\text { constipation (\%) }\end{array}$ & $\begin{array}{l}\text { Improvement in } \\
\text { continence (\%) }\end{array}$ & $\begin{array}{l}\text { Follow-up } \\
\text { (mo) }\end{array}$ & $\begin{array}{c}\text { Postoperative } \\
\text { complications (\%) }\end{array}$ \\
\hline Houry et al. [4] & 1986 & 18 & 17.0 & 6.0 & 44.0 & 18.0 & NR \\
\hline Abulafi et al. [9] & 1990 & 22 & 5.0 & 9.0 & 75.0 & 29.0 & 28.0 \\
\hline Senapati et al. [6] & 1994 & 32 & 21.0 & 0 & 46.0 & 21.0 & 6.0 \\
\hline Lechaux et al. [3] & 1995 & 85 & 13.5 & 0 & 69.0 & 33.0 & 14.0 \\
\hline Pescatori et al. [13] & 1998 & 33 & 21.0 & 15.0 & 35.0 & 39.0 & 45.0 \\
\hline Watkins et al. [7] & 2003 & 52 & 10.0 & NR & 83.3 & 61.4 & 25.0 \\
\hline Tsunoda et al. [1] & 2003 & 31 & 13.0 & 0 & 63.0 & 39.0 & 13.0 \\
\hline Present study & 2010 & 19 & 15.8 & 5.3 & 63.2 & 54.0 & 0 \\
\hline
\end{tabular}

NR, not reported.

cated as emergency surgery for strangulated rectal prolapsed, with satisfactory results [9].

In this study, the mean age was $67.2 \pm 16.6$ years (range, 43 to 89 years). Of all 19 patients, 7 (37\%) were ASA II and III, 5 (26\%) were sexually active males, and $9(47 \%)$ were older than 70 years (5 of them were combined with ASA II and III). One patient (5\%), 84 years old, died of sepsis due to preexistent pneumonia on the 26th day after the procedure. No other mortalities or morbidities related to the operation were noted. Some reports revealed low operative mortality for the Delorme operation, ranging from 0 to
$3.5 \%[2,4,7,8,10]$. Mortality for the abdominal rectopexy and the low anterior resection has been reported to be less than $3 \%$ $[11,12]$. No major postoperative complications, such as anastomosis stricture or dehiscence and bleeding, were observed in the present study. Many reports demonstrated that some patients underwent urination difficulty during the immediate postoperative period. In our series, this complication was prevented by postoperative bladder training with a Foley catheter $[2,3,5,8]$.

Recurrence of the rectal prolapse was observed in 3 patients (15.8\%) (at 6, 18, and 29 months, respectively, after the operation) 
in this study. Review of the literature shows that the incidence of recurrence for the Delorme procedure is 6.8 to $22 \%[3,7-9,13,14]$ and that for the Altemeier procedure is 0 to $16 \%$ [15-18]. Transabdominal procedures show low recurrence rates of 0 to $7 \%$ [1924]. Failures with the Delorme operation have most often been associated with accompanying local perineal pathophysiology, such as serious sphincter dysfunction, chronic diarrhea, perineal descent, or colonic conditions that may render complete mucosectomy impossible. Incomplete mucosectomy and pelvic floor defects have been associated with high recurrence. However, recurrence is easily treated with a repeat procedure [13].

Many reports in the literature show that the Delorme operation improves continence (Table 4) $[1,3,4,7,8,10,14]$. In the present study, improved continence occurred in $63.2 \%$ of the patients who described incontinence before surgery. Even though the patients had incontinence postoperatively, the symptom was very mild (CCIS 0 in 7 patients, 4 in 3, 6 in 3, 8 in 1, and 9 in 2). Part of the reason for this may be the cessation of mucous leakage from the prolapsed, which had previously been interpreted as incontinence. The reduced resting pressure in patients with a rectal prolapse is undoubtedly improved in some after surgery, perhaps simply because the anus is no longer kept open by the rectal prolapse, perhaps also through abolition of the rectoanal inhibitory reflex triggered by the presence of an internal intussusception such as a fecal bolus in the rectum [6]. Also, improved continence occurs in spite of the observation that no change in anal sphincter pressure occurs and in spite of reductions measured in rectal compliance after the operation [8].

In this study, no patient reported constipation preoperatively. Only 1 patient (5.3\%), who did not have constipation preoperatively, developed constipation after the operation. A review of the literature showed that constipation following abdominal procedures occurred in 27 to $47 \%$ of all patients $[11,12]$. Rectal denervation is probably an important factor in the etiology of defecatory problems. However, the ligament that can cause rectal denervation is not sectioned with the Delorme's perineal technique, and this prevents constipation from developing; constipation may even improve after surgery [12]. For other authors, the improvement of constipation may result from reduced rectal compliance after surgery, which explains the increase in defecatory frequency. Also, a rectal mucosectomy may exert a significant effect on proximal colonic motility, with a higher frequency of rectal filling and, hence, improved constipation [25]. For these reasons, the Delorme's procedure has been recommended for the management of constipation associated with internal rectal intussusceptions $[3,26]$.

Unfortunately, we did not perform an anorectal physiologic study, including anal manometry, pudendal nerve conduction, and cinedefecography, in our series. Thus, our study has some limitations in terms of other conditions or urogynecological problems, which might affect the result.

In conclusion, the Delorme's procedure is a perineal technique that resolves the complete rectal prolapse with a low surgical risk and little morbidity. The procedure is associated with a marked improvement in anal continence, relatively low relapse rates, and a low incidence of postoperative constipation. This allows us to conclude that this procedure still has its own role in selected patients.

\section{CONFLICT OF INTEREST}

No potential conflict of interest relevant to this article was reported.

\section{REFERENCES}

1. Tsunoda A, Yasuda N, Yokoyama N, Kamiyama G, Kusano M. Delorme's procedure for rectal prolapse: clinical and physiological analysis. Dis Colon Rectum 2003;46:1260-5.

2. Watts AM, Thompson MR. Evaluation of Delorme's procedure as a treatment for full-thickness rectal prolapse. Br J Surg 2000;87: 218-22.

3. Lechaux JP, Lechaux D, Perez M. Results of Delorme's procedure for rectal prolapse. Advantages of a modified technique. Dis Colon Rectum 1995;38:301-7.

4. Houry S, Lechaux JP, Huguier M, Molkhou JM. Treatment of rectal prolapse by Delorme's operation. Int J Colorectal Dis 1987;2: 149-52.

5. Tobin SA, Scott IH. Delorme operation for rectal prolapse. Br J Surg 1994;81:1681-4.

6. Jorge JMN, Wexner SD. Etiology and management of fecal incontinence. Dis Colon Rectum 1993;36:77-97.

7. Senapati A, Nicholls RJ, Thomson JP, Phillips RK. Results of Delorme's procedure for rectal prolapse. Dis Colon Rectum 1994;37: 456-60.

8. Watkins BP, Landercasper J, Belzer GE, Rechner P, Knudson R, Bintz $\mathrm{M}$, et al. Long-term follow-up of the modified Delorme procedure for rectal prolapse. Arch Surg 2003;138:498-502.

9. Jordán JC, Fernández C, Díaz F, Alós R, Buch E, Roig JV. Delorme's procedure in a case of strangulated rectal prolapse. Cir Esp 1999;66:339-40.

10. Abulafi AM, Sherman IW, Fiddian RV, Rothwell-Jackson RL. Délorme's operation for rectal prolapse. Ann R Coll Surg Engl 1990; 72:382-5.

11. Mann CV, Hoffman C. Complete rectal prolapse: the anatomical and functional results of treatment by an extended abdominal rectopexy. Br J Surg 1988;75:34-7.

12. Holmström B, Brodén G, Dolk A. Results of the Ripstein operation in the treatment of rectal prolapse and internal rectal procidentia. Dis Colon Rectum 1986;29:845-8.

13. Kling KM, Rongione AJ, Evans B, McFadden DW. The Delorme procedure: a useful operation for complicated rectal prolapse in the elderly. Am Surg 1996;62:857-60.

14. Pescatori M, Interisano A, Stolfi VM, Zoffoli M. Delorme's operation and sphincteroplasty for rectal prolapse and fecal incontinence. Int J Colorectal Dis 1998;13:223-7. 
15. Altemeier WA, Culbertson WR, Schowengerdt C, Hunt J. Nineteen years' experience with the one-stage perineal repair of rectal prolapse. Ann Surg 1971;173:993-1006.

16. Agachan F, Reissman P, Pfeifer J, Weiss EG, Nogueras JJ, Wexner SD. Comparison of three perineal procedures for the treatment of rectal prolapse. South Med J 1997;90:925-32.

17. Kim DS, Tsang CB, Wong WD, Lowry AC, Goldberg SM, Madoff $\mathrm{RD}$. Complete rectal prolapse: evolution of management and results. Dis Colon Rectum 1999;42:460-6.

18. Kimmins MH, Evetts BK, Isler J, Billingham R. The Altemeier repair: outpatient treatment of rectal prolapse. Dis Colon Rectum 2001;44:565-70.

19. Deen KI, Grant E, Billingham C, Keighley MR. Abdominal resection rectopexy with pelvic floor repair versus perineal rectosigmoidectomy and pelvic floor repair for full-thickness rectal prolapse. Br J Surg 1994;81:302-4.

20. Huber FT, Stein H, Siewert JR. Functional results after treatment of rectal prolapse with rectopexy and sigmoid resection. World J Surg 1995;19:138-43.
21. Stevenson AR, Stitz RW, Lumley JW. Laparoscopic-assisted resection-rectopexy for rectal prolapse: early and medium follow-up. Dis Colon Rectum 1998;41:46-54.

22. Bruch HP, Herold A, Schiedeck T, Schwandner O. Laparoscopic surgery for rectal prolapse and outlet obstruction. Dis Colon Rectum 1999;42:1189-94.

23. Kellokumpu IH, Vironen J, Scheinin T. Laparoscopic repair of rectal prolapse: a prospective study evaluating surgical outcome and changes in symptoms and bowel function. Surg Endosc 2000; 14:634-40.

24. Madbouly KM, Senagore AJ, Delaney CP, Duepree HJ, Brady KM, Fazio VW. Clinically based management of rectal prolapse. Surg Endosc 2003;17:99-103.

25. Watts JD, Rothenberger DA, Buls JG, Goldberg SM, Nivatvongs S. The management of procidentia. 30 years' experience. Dis Colon Rectum 1985;28:96-102.

26. El-Sibai O, Shafik AA. Cauterization-plication operation in the treatment of complete rectal prolapse. Tech Coloproctol 2002;6: $51-4$. 